\title{
Level of Knowledge and Awareness of Halitosis in the Dental Medicine Students
}

\author{
Muhammad Arya Rizkianto ${ }^{1}$, Novita ${ }^{1}$, Cindy Shavia ${ }^{1}$, Gempita Anargia ${ }^{1}$, Farah Maulidya Titani ${ }^{1}$, Titian \\ Fauzi Nurrahman ${ }^{1}$, Regina Purnama Dewi Iskandar ${ }^{2}$ \\ ${ }^{1}$ Undergraduate Student of Dental Medicine, Department Dental Public Health, Faculty of Dental Medicine, \\ Universitas Airlangga Indonesia, ${ }^{2}$ Primary Health Care Research group, Faculty of Dental Medicine, Universitas \\ Airlangga Indonesia
}

\begin{abstract}
Background: Halitosis is a general term that means bad odor in the oral cavity that is difficult to treat due to poor oral health and is a problem affecting $50 \%$ of the adult population The impact of halitosis is closely related to the psychological and social effects of a person.
\end{abstract}

Purpose: To find out the level of knowledge and awareness of Dental Medicine Students of Universitas Airlangga about halitosis and the benefits of the perception and level of awareness of halitosis as a reference in carrying out health promotion.

Method: This research will use a cross sectional random sampling study. The survey or questionnaire was distributed to 100 students from class of 2014 to 2019 Faculty of Dental Medicine, Universitas Airlangga, Surabaya, Indonesia.

Result: The results of this study shows that the level of halitosis knowledge in pre-clinic students shows that $57 \%$ had a proper knowledge and $43 \%$ had a poor knowledge. While clinical students have a $46 \%$ poor knowledge result and $54 \%$ with proper knowledge. For the awareness of halitosis in pre-clinic students shows that $91 \%$ had a proper awareness and only $9 \%$ with poor awareness.

Conclusion: The average score of the respondents on poor knowledge of halitosis and poor awareness of halitosis, so health promotion that will be carried out can be emphasized on counseling about halitosis.

Keyword: Halitosis, Psychological and Social impacts, Knowledge about Halitosis.

\section{Introduction}

Halitosis is a general term that means bad odor in the oral cavity that is difficult to disappear due to poor oral health ${ }^{1}$. Halitosis comes from the Latin word "halitus" meaning breath and the Greek word "osis" which means

\section{Corresponding Author:}

\section{Regina Purnama Dewi Iskandar}

Jl. Prof. Dr. Moestopo No. 47

Phone Numbers: (+6231) 5030255, 5020256

Facsimile Numbers: (+6231) 5020256

e-mail: regina_pdewi@hotmail.com abnormal or disease. Halitosis is a term for defining bad odor from breathing. The unpleasant odor caused by the release of Volatile Sulfur Compounds (VSCs) caused by the decay activity of gram-negative microorganisms ${ }^{2}$. Halitosis can be divided into 3 types, namely true halitosis, pseudohalitosis and halitophobia ${ }^{3}$.

The cause of halitosis is still unknown, but most of the causes are food scraps left in the oral cavity which are then processed by the oral flora ${ }^{4}$ Of particular concern are saliva, tongue, interdental areas and teeth ${ }^{5,6}$. In addition, halitosis can also be caused by abnormalities in the oral cavity or systemic abnormalities or abnormalities in the extraoral ${ }^{7}$. Common causes of halitosis (more than $80 \%$ ) are stomatological disorders such as calculus ${ }^{8}$, chronic 
gingivitis, periodontitis ${ }^{9}$, caries $^{10}$, poor oral hygiene ${ }^{11}$, stomatitis caused by bacteria and fungi, inflammation of the mucous membranes and bones, tumors, etc ${ }^{12}$. Other disorders that can also trigger halitosis are open pulp teeth, post extraction sores ${ }^{13}$, dentures that are rarely removed and cleaned ${ }^{14}$, cysts, oral cancer and food impaction ${ }^{15}$.

The impact of halitosis is closely related to the psychological and social effects of a person. Unpleasant breath during communication can be an influence on a person's social life and psychological health ${ }^{16}$. Bad breath can also cause phobias, depression, excessive worries, behavior changes and can affect self confidence ${ }^{17}$. The social impact of halitosis has been studied in other studies where women tend to be ashamed of halitosis. More and more women feel that they cannot reach their academic goals because of bad breath. Women are more aware of their bad breath. The use of oral hygiene aids greatly influences individual social behavior and is very important for individuals who face insecurities about their bad breath in social interactions ${ }^{18}$. In preventing halitosis, an individual's knowledge and awareness of halitosis is needed.

Knowledge is the result of knowing obtained by humans by sensing an object. Knowledge becomes the main domain for the creation of human behavior ${ }^{19}$. While awareness is a form of someone's readiness to face all forms of surrounding events and cognitive events including memory, thoughts, feelings and physical. Both of these are interrelated and play an important role in preventing halitosis. Therefore, in this study the authors wanted to know the knowledge and awareness of halitosis in the community with samples taken from students of the Faculty of Dental Medicine, Universitas Airlangga. The data can then be used to develop a health promotion program on halitosis.

\section{Material and Method}

In this study a descriptive cross-sectional study method was used and the sample was taken randomly. This study was approved by the ethics commission of the Faculty of Dental Medicine, Universitas Airlangga. The subjects and locations used for this study were 100 Dental Medicine students at Universitas Airlangga in Surabaya from the class of 2014 to the class of 2019 (Preclinical and clinical students). The research instrument used to collect data in the form of questionnaires. Questionnaires are data collection techniques carried out by giving a set of questions or statements to other people who are subject to answer ${ }^{20}$. The questions that will be used in this study are questions from a journal that had previously been made by Mubayrik ${ }^{21}$ and made several changes. Questions were shared using Google Form and filling was done in private and each sample filled in individually. The question format provided contains 3 pages consisting of identity data and informed consent, questions about self-awareness about halitosis and the last page contains questions about knowledge about halitosis. Total questions provided are 13 questions. The research variables seen in this study are knowledge about halitosis and awareness of halitosis.

\section{Result}

Table I: Fully Answered Questionnaire

\begin{tabular}{|c|c|c|c|c|c|c|}
\hline & \multicolumn{6}{|c|}{ Cases } \\
\hline & \multicolumn{2}{|c|}{ Valid } & \multicolumn{2}{|c|}{ Missing } & \multicolumn{2}{|c|}{ Total } \\
\hline & $\mathbf{N}$ & Percent & $\mathbf{N}$ & Percent & $\mathbf{N}$ & Percent \\
\hline $\begin{array}{l}\text { Self_Evaluation_of_Halitosis* } \\
\text { Sex }\end{array}$ & 100 & $100.0 \%$ & 0 & $0.0 \%$ & 100 & $100.0 \%$ \\
\hline $\begin{array}{l}\text { Self_Evaluation_of_Halitosis * } \\
\text { Education }\end{array}$ & 100 & $100.0 \%$ & 0 & $0.0 \%$ & 100 & $100.0 \%$ \\
\hline $\begin{array}{l}\text { Knowledge_About_Halitosis * } \\
\text { Sex }\end{array}$ & 100 & $100.0 \%$ & 0 & $0.0 \%$ & 100 & $100.0 \%$ \\
\hline $\begin{array}{l}\text { Knowledge_About_Halitosis * } \\
\text { Education }\end{array}$ & 100 & $100.0 \%$ & 0 & $0.0 \%$ & 100 & $100.0 \%$ \\
\hline
\end{tabular}


Table II: Research Results

\begin{tabular}{|c|c|c|c|c|c|c|c|c|c|c|c|c|c|}
\hline & & \multicolumn{6}{|c|}{ Self_Evaluation_of_Halitosis } & \multicolumn{6}{|c|}{ Knowledge_about_Halitosis } \\
\hline & & \multicolumn{2}{|c|}{ Poor } & \multicolumn{2}{|c|}{ Proper } & \multicolumn{2}{|c|}{ Total } & \multicolumn{2}{|c|}{ Poor } & \multicolumn{2}{|c|}{ Proper } & \multicolumn{2}{|c|}{ Total } \\
\hline \multirow{3}{*}{ Education } & Pre-Clinic & 8 & $9 \%$ & 79 & $91 \%$ & 87 & $100 \%$ & 37 & $43 \%$ & 50 & $57 \%$ & 87 & $100 \%$ \\
\hline & Clinic & 2 & $15 \%$ & 11 & $85 \%$ & 13 & $100 \%$ & 6 & $46 \%$ & 7 & $54 \%$ & 13 & $100 \%$ \\
\hline & Total & 10 & $10 \%$ & 90 & $90 \%$ & 100 & $100 \%$ & 43 & $43 \%$ & 57 & $57 \%$ & 100 & $100 \%$ \\
\hline \multirow{3}{*}{ Sex } & Men & 2 & $8 \%$ & 24 & $92 \%$ & 26 & $100 \%$ & 16 & $62 \%$ & 10 & $38 \%$ & 26 & $100 \%$ \\
\hline & Women & 8 & $11 \%$ & 66 & $89 \%$ & 74 & $100 \%$ & 27 & $36 \%$ & 47 & $64 \%$ & 74 & $100 \%$ \\
\hline & Total & 10 & $10 \%$ & 90 & $90 \%$ & 100 & $100 \%$ & 43 & $43 \%$ & 57 & $57 \%$ & 100 & $100 \%$ \\
\hline
\end{tabular}

In table 1, it can be seen the results of the questionnaire that has been summarized and analyzed. In the questionnaire, questions about self-evaluation of halitosis range or awareness of halitosis are represented by 4 questions which include how to evaluate halitosis in yourself, how to confirm the diagnosis of halitosis, how to cope with halitosis according to individual views and what action will be taken for acquaintances who experience halitosis. The questions are available in multiple choices from a through $\mathrm{d}$ and whoever answer a will be graded by 3 and whoever answer $d$ will be scored 0 . Individual scores of more than 7 will be rated proper and less than 7 will be judged poorly. After analyzing the data, the results of pre-clinical students who have proper awareness about halitosis by $91 \%$ and clinical students by $85 \%$ and overall respondents $90 \%$ have proper awareness of hallitosis. Furthermore, for the variable knowledge about individual halitosis with scores 9 to 14 are considered proper and less than 8 means poor knowledge about halitosis. The results of pre-clinical students with proper knowledge by $57 \%$ and clinical students who have good knowledge by $54 \%$. The presentation of the knowledge of Dental Medicine students of Universitas Airlangga to halitosis shows that $57 \%$ had a proper knowledge and the rest was poor or lack of knowledge. After testing the two variables, the authors also compared sex to awareness and knowledge of halitosis. The percentage of individual awareness of halitosis was higher in men at $92 \%$ while in women at $89 \%$. This is contrary to students knowledge, women have better presentations of $64 \%$ and men by $38 \%$.

\section{Discussion}

The results of the first part of the research about Halitosis Knowledge of Pre-Clinical and Clinical Students shows that the level of halitosis knowledge in pre-clinical students with poor knowledge is $43 \%$ and $57 \%$ had a proper knowledge. While clinical students have a $46 \%$ bad knowledge result and $54 \%$ proper knowledge. With the results of this study it was found that the level of knowledge of clinical students is lower than pre-clinic students. This means that it is not in accordance with the hypothesis that clinical students should have more and better knowledge about halitosis.

The results of this study are based on literature by Cassiano Kuchenbecker Rösing \& Walter Loesche ${ }^{22}$, who stated that everyone in the field of dentistry should pay more particular attention to halitosis. However, the science behind understanding halitosis is still low. Some clinical approaches are based on opinion. As a dentist must have knowledge about current halitosis, diagnosis and treatment modalities to meet the needs of patients either consciously or knowledgeably with this problem. According to the results of Cameira N.J ${ }^{15}$ 's research, students showed a lack of proper knowledge about halitosis and reported an inadequate level of education on the subject, which was inconsistent with the results of our study. In general, providing knowledge about halitosis is very important because it can be a manifestation of several diseases. Therefore early diagnosis seems to be a must. Conducting scientific publications and clinical guidance on this issue may be very helpful to health practitioners.

Knowing that majority of causes of halitosis are oral based, dentists must become primary health professionals in screening and managing halitosis in patients who complain about the disease. Poor education can lead to a lack of confidence by dental professionals and an unsatisfactory response to patient needs ${ }^{23}$. On the other hand, this problem is an obligation for a dentist to identify and develop knowledge in the field of dentistry, 
to provide balanced scientific information to patients and to increase the knowledge of dentistry students. Halitosis is a recognizable diseasae that requires professional attention ${ }^{24}$. To overcome this, dental schools must commit to give their students a strong emphasis on this condition. A self-evaluation check might be a starting point for a change. Furthermore, the results of the second part of research about Halitosis Awareness in Pre-Clinical and Clinical Students shows that $91 \%$ of the pre-clinical students had a proper awareness and only $9 \%$ had a poor awareness. While clinical students had a poor knowledge result of $15 \%$ and proper knowledge of $85 \%$. With the results of this study it was found that the level of awareness of clinical students is lower than pre-clinical students. Based on Mubayrik A. ${ }^{21}$ study, found a relatively low level of self-reported halitosis awareness, but a much larger proportion indicates that bad breath is a problem for people around them. Most respondents indicated that they would overcome bad breath by covering up rather than treating the cause. The results obtained are not in accordance with the hypothesis where it is expected that clinical students have a higher awareness than preclinical students. As in previous studies which showed that the first, second, third and fourth grade students experienced a significant increase in awareness of halitosis. This is comparable to the experience and education training of dental students who are getting more and more experienced on this field $^{25}$.

In the results of the third part of research about Halitosis Knowledge in Female and Male Students shows that the level of halitosis knowledge in female students with bad knowledge is $36 \%$ and proper knowledge is $64 \%$. While male students have a poor knowledge result of $62 \%$ and poor knowledge of $38 \%$. With the results of this study found that the level of knowledge of male students is lower than female students.

The results of the fourth part of the research about Halitosis Awareness in Female and Male Students showed that the level of halitosis awareness in female students had a result of $11 \%$ with poor awareness and $89 \%$ with proper awareness. While male students had $8 \%$ with poor awareness and $92 \%$ with proper awareness. With the results of this study it was found that the level of awareness of male students was lower than that of female students. The results of the above study in accordance with previous studies stated that female students had an awareness to maintain teeth and oral health better than male students ${ }^{25}$. This could happen because women prefer to use dental floss and mouth wash than men. Some supporting factors include the fact that women take more care and attention of their body and appearance compared to $\mathrm{men}^{26}$.

\section{Conclusion}

Our results show that the evaluation rate and awareness of the Unair Dental Medicine students about bad breath or halitosis is fairly good, with an average score of respondents towards poor knowledge of halitosis by $43 \%$ and proper knowledge by $57 \%$ and on the results for evaluating awareness of halitosis, the result of poor awareness of halitosis is $10 \%$ and those who have proper awareness are $90 \%$. The evaluation obtained in this study where there is a large gap from the comparison of male and female students who are in the Faculty of Dental Medicine of Universitas Airlangga and there is an uneven distribution between pre-clinical and clinical students, causing a large enough comparation.

Conflict of Interest: There are no conflicts of interest.

Source of Funding: Self-Funding

Ethical Clearance: Approved

\section{References}

1. Kukkamalla DMA, Cornelio DSM, Mahalinga Bhat DK, Avadhani DM, Goyal DR. HALITOSIS-A Social Malady. IOSR J Dent Med Sci. 2014;13(5):55-61.

2. Alshehri FA. Knowledge and attitude of Saudi individuals toward self-perceived halitosis. SAUDI J Dent Res. 2016;

3. Oeding M. Halitosis: A Clinical Review. Acad Dent Learn OSHA Train. 2012;

4. Arora L, Sharma A. A Study to find out the Dental and Associated Psychosocial Factors in Patients of Halitosis. 2014;(January 2012).

5. Sopianah Y, Sabilillah MF, Oedijani O. The effects of audio-video instruction in brushing teeth on the knowledge and attitude of young slow learners in Cirebon regency. Dent J (Majalah Kedokt Gigi). 2017;50(2):66-70.

6. Nelonda R, Setiadhi R. Management of chronic traumatic ulcer mimicking oral squamous cell carcinoma on the tongue. Dent J (Majalah Kedokt Gigi). 2018;51(2):76. 
7. Ghapanchi J, Darvishi M, Mardani M, Sharifian N. Prevalence and cause' $\mathrm{s}$ of bad breath in patients attended Shiraz dentistry school . A cross sectional study. 2012;53:12051-4.

8. Nasution AH, Amatanesia DD. Correlation of salivary phosphorous level to dental calculus accumulation on patients of the periodontology installation in dental hospital of USU. J Phys Conf Ser. 2018;1116(5).

9. Ramadhany S, Achmad H, Handayani H, Tanumihardja M, Singgih MF, Inayah $\mathrm{NH}$, et al. Formulation of ethanol extract (Myrmecodia pendans) as an antibacterial streptococcus mutans in chewable lozenges for children with early childhood caries. Syst Rev Pharm [Internet]. 2020;11(4):252-7.

10. Lendrawati L, Pintauli S, Rahardjo A, Bachtiar A, Maharani DA. Risk factors of dental caries: Consumption of sugary snacks among indonesian adolescents. Pesqui Bras Odontopediatria Clin Integr. 2019;19(1):1-8.

11. Daeng Pasiga B, Samad R, Pratiwi R. Relationship of oral aesthetic assessment according to self perception with oral malocclusion condition of high school students in sidrap district, south sulawesi Indonesia . Brazilian Dent Sci [Internet]. 2019;22(4):450-7.

12. Herman S, Mizgała E, Herman J, Ura-Sabat K, Misiołek M. Halitoza-przyczyny, diagnostyka, leczenie. High Sch Pulse. 2016;10(4):13-7.

13. Primasari A, Ria N, Sutadi H. Vertical cephalic index, dental arch and palatal depth measurement: A study in Bataknese children. Pesqui Bras Odontopediatria Clin Integr. 2019;19(1):1-6.

14. Widjiastuti I, Rudyanto D, Yuanita T, Bramantoro $\mathrm{T}$, Widodo WA. Cleaning efficacy of root canal irrigation with positive and negative pressure system. Iran Endod J. 2018;13(3):398-402.

15. Rao MUS, Utharkar SM, Sundaram CS. Halitosis: Classification, Causes and diagnostic as well as Treatment Approach-A Review. Res J Pharm Technol. 2015;8(12):1707.
16. Al Sadhan SA. Self-perceived halitosis and related factors among adults residing in Riyadh, Saudi Arabia. A cross sectional study. Saudi Dent J. 2016;28(3):118-23.

17. Yaegaki K, Coil JM. (Examen, classification et traitement de la mauvaise haleine : perspectives cliniques). 2014;66(January):257-61.

18. de Jongh A, van Wijk AJ, Horstman M, de Baat C. Self-perceived halitosis influences social interactions. BMC Oral Health. 2016;16(1):1-7.

19. Notoatmojo S. Prinsip-prinsip Dasar Ilmu Kesehatan Masyarakat. 2010;

20. Hendryadi H. Metode pengumpulan data. 2014;(01):1-5.

21. Bin Mubayrik A, Al Hamdan R, Al Hadlaq EM, AlBagieh H, Alahmed D, Jaddoh H, et al. Selfperception, knowledge and awareness of halitosis among female university students. Clin Cosmet Investig Dent. 2017;9:45-52.

22. Rösing CK, Loesche W. Halitosis: An overview of epidemiology, etiology and clinical management. Braz Oral Res. 2011;25(5):466-71.

23. Cameira Nunes J, Martínez-Sahuquillo Á, Cameira MJ, Dias Marques H. Halitosis: Are dentists being prepared for this challenge? - A questionnaire survey in a dental school. Rev Port Estomatol Med Dent e Cir Maxilofac. 2011;52(3):142-6.

24. Armstrong BL, Sensat ML, Stoltenberg JL. Halitosis: a review of current literature. J Dent Hyg. 2010;84(2):65-74.

25. Ahamed S, Moyin S, Punathil S, Patil NA, Kale VT, Pawar G. Evaluation of the Oral Health Knowledge, Attitude and Behavior of the Preclinical and Clinical Dental Students. J Int oral Heal JIOH. 2015;7(6):65-70.

26. Khami MR, Virtanen JI, Jafarian M, Murtomaa $\mathrm{H}$. Oral health behaviour and its determinants amongst Iranian dental students. Eur J Dent Educ. 2007;11(1):42-7. 